\title{
Project Career: Perceived benefits of iPad apps among college students with Traumatic Brain Injury (TBI)
}

\author{
K. Jacobs ${ }^{\mathrm{a}, *}$, A. Leopold ${ }^{\mathrm{b}}$, D.J. Hendricks ${ }^{\mathrm{c}}$, E. Sampson ${ }^{\mathrm{c}}$, A. Nardone ${ }^{\mathrm{a}}$, K.B. Lopez ${ }^{\mathrm{d}}$, P. Rumrill ${ }^{\mathrm{d}}$, \\ C. Stauffer ${ }^{\mathrm{d}}$, E. Elias ${ }^{\mathrm{b}}$, M. Scherer ${ }^{\mathrm{e}}$ and J. Dembe ${ }^{\mathrm{d}}$ \\ ${ }^{\mathrm{a}}$ Boston University, Boston, MA, USA \\ ${ }^{\mathrm{b}}$ JBS International, Inc., Bethesda, MD, USA \\ ${ }^{\mathrm{c}}$ West Virginia University, Morgantown, WV, USA \\ ${ }^{\mathrm{d}}$ Kent State University, Kent, OH, USA \\ ${ }^{\mathrm{e}}$ University of Rochester, Rochester, NY, USA
}

Received 3 July 2016

Accepted 9 March 2017

\begin{abstract}
.
BACKGROUND: Project Career is an interprofessional five-year development project designed to improve academic and employment success of undergraduate students with a traumatic brain injury (TBI) at two- and four-year colleges and universities. Students receive technology in the form of iPad applications ("apps") to support them in and out of the classroom. OBJECTIVE: To assess participants' perspectives on technology at baseline and perceived benefit of apps after 6 and 12 months of use.

METHODS: This article address a component of a larger study. Participants included 50 college-aged students with traumatic brain injuries. Statistical analysis included data from two Matching Person and Technology (MPT) assessment forms, including the Survey of Technology Use at baseline and the Assistive Technology Use Follow-Up Survey: Apps Currently Using, administered at 6- and 12-months re-evaluation. Analyses included frequencies and descriptives.

RESULTS: Average scores at baseline indicated positive perspectives on technology. At 6 months, quality of life (67\%) and academics (76\%) improved moderately or more from the use of iPad apps. At 12 months, quality of life (65\%) and academics $(82 \%)$ improved moderately or more from the use of iPad apps.

CONCLUSION: Students with a TBI have positive perspectives on technology use. The results on perceived benefit of apps indicated that students with a TBI (including civilians and veterans) report that the apps help them perform in daily life and academic settings.
\end{abstract}

Keywords: Cognitive support technology, employment, note taking, study support, Matching Person and Technology (MPT) Assessment

\section{Introduction}

One of the leading causes of death and disability in the United States is traumatic brain injury (TBI) [1]. According to the most recent statistics released by the

${ }^{*}$ Address for correspondence: Karen Jacobs, 635 Commonwealth Avenue, Boston, MA 02215, USA. Tel.: +1 617353 7516; E-mail: kjacobs@bu.edu.
Centers for Disease Control and Prevention (CDC) in a longitudinal study from 2001-2010, rates of TBI-related emergency department visits increased by $70 \%$, hospitalization rates increased by $11 \%$, and death rates decreased by $7 \%$ [1]. Individuals with mild and moderate TBIs are most likely to survive [2, 3]. This data provides support for the claim that recent advances in medical care are leading to improved survival rates in this population, though survivors then 
face disabling effects of a TBI which could persist for a lifetime. TBI is a major public health problem that affects civilian, military, and veteran populations. Among military and veterans there are more than 344,000 service members who have incurred a TBI since 2000 with $82.3 \%$ categorized as mild [4].

Individuals with a TBI commonly experience cognitive impairments (e.g. memory, organization, processing speed), movement problems, impairments in sensation (e.g. vision, hearing), and/or emotional functioning issues (e.g. personality changes, depression) [1]. Many continue to experience these negative effects as part of a long-term sequela. In fact, one prospective study of 1,802 patients with a TBI hospitalized in Colorado found that $58.8 \%$ of participants reported at least one functional need during the year post-injury [5]. More than $40 \%$ reported that at least one need was unmet at one-year post-injury. The most commonly reported needs at one-year post-injury included improving cognition, managing stress, controlling temper, improving job skills, and managing money [5].

Understandably, these long-term challenges have been reported as major concerns among high school and college students with a TBI as they return to school and transition into the workforce [6-8]. However, studies indicate that these students are not currently receiving the support they need to succeed. One qualitative longitudinal study collected data from 33 participants with a moderate to severe TBI, ages 17-23 years old. Despite their diagnosis, $27.2 \%$ did not receive special education services and $48.5 \%$ did not receive transition services [8]. Sometimes, school staff's fear of stigmatizing the student contributed to decisions not to provide services. Although the vast majority of participants received regular or modified high school diplomas (73\% and $24 \%$, respectively), some reported receiving passing grades for the sake of graduating rather than representing their true mastery level of class content and skills. Only 54\% of participants attended training programs or college post-high school [8].

An electronic survey study of 35 college students with a TBI inquired about the academic

challenges they faced as a result of their injuries [6]. On average, students reported 9.69 difficulties ( $\mathrm{SD}=3.79$, range of 2 to 15 ) [6]. Common complaints included problems with memory $(82.9 \%)$, organization $(77.1 \%)$, decision-making (68.6\%), and attention $(65.7 \%)$. Each of thesehas a clear and negative impact on a college students' success in the classroom. Other reported difficulties related to academic success included fatigue $(74.3 \%)$, headaches $(68.6 \%)$, anger $(71.7 \%)$, depression $(71.4 \%)$, and mood changes (57.2\%). When considering use of campus resources or supports, many participants had never heard of or accessed campus disability services $(44.8 \%)$, campus counseling services $(77.4 \%)$, or campus medical services $(77.4 \%)$ [6].

Ponsford et al. (2014), conducted a 10-year longitudinal study to better understand the long-term functional consequences of TBI. One hundred and forty-one patients with a TBI were assessed at two, five-, and 10-years post-injury using a functional outcome questionnaire. Approximately $60 \%$ of participants reported negative changes in cognition, communication, behavior, and emotional functioning at all three time points. Less than $50 \%$ of the sample were employed at each time point and, overall, problems reported at two-years post-injury persisted at 10-years post-injury [9].

It is clear that timely and effective interventions are needed to assist students with a TBI as they return to school and enter or re-enter the workforce. Given the high rates of technology ownership and use in college students, [10] one non-stigmatizing form of intervention hypothesized to help students compensate for cognitive impairments includes assistive technology. Specifically, cognitive support technologies (CST) have been used to aid college students with a TBI with daily tasks in academic and vocational settings [7]. Cognitive support technology is "a special class of assistive technology products designed to increase, maintain or improve functional capabilities for individuals whose cognitive changes limit their effective performance of daily activities" [16]. Leopold, Lourie, Petras, and Elias (2015), completed a qualitative analysis of 28 studies published between 2000 and 2015 that used CST with individuals with a TBI. Results demonstrated successful use of CST by individuals with a TBI to support a variety of cognitive functions, including memory [11]. The authors recommended individualized application of CST based on specific needs rather than uniform application among groups of individuals with the same diagnosis.

Findings from Hartmann (2009), suggest that training in and use of individualized CST can also be effective in vocational settings [12]. In this case study, a 32-year old male paralegal with a mild TBI was diagnosed with executive function difficulties including short-term memory and sequential organizational deficits at three-months post-injury. He was subsequently referred to an occupational therapist, who 
introduced him to a variety of assistive technologies based on his needs and trained him in the use of each tool. One-month post-referral, he demonstrated substantial improvements in work performance related to productivity, ease and accuracy of note-taking, reading speed, and ability to sustain reading for prolonged periods of time. When he did not use the technology, his work productivity returned to pre-intervention levels. Holzberg (2001), also recommended the use of assistive technology provided by school-to-work transition programs and supported employment as part of best practices for assisting individuals with a TBI in successfully completing academic programs as well as gaining and maintaining employment [13].

While evidence supports the effectiveness of CST, the question of users' perception of its usefulness still remains [14]. The current study examined perceived benefits of CST in the form of iPad applications ("apps") among college students with a TBI after 6 and 12 months of use. The apps for which data was collected included programs for note-taking, study support, planning, organization, behavioral/psychological support, and recreational activities. See Table 1 for list of Apps used. This study used retrospective data collected as part of a demonstration project called Project Career currently being conducted at Kent State University, Boston University, and West Virginia University. Project Career is an interprofessional five-year development project funded by the National Institute for Disability, Independent Living, Rehabilitation and Research (NIDILRR). The project is designed to improve the academic and employment outcomes of undergraduate students with a TBI at two- and four-year colleges and universities through a combination of assistive technology on iPads, academic mentorship, and individualized career counseling services. As part of Project Career, all participants are provided with an iPad at no cost. The iPads serve as (a) a means to provide CST in the form of apps and (b) a virtual platform to provide coaching, education, counseling, and career mentoring services in order to address academic challenges and maximize students' career readiness. The iPad device is highly mobile, easy to use, connects easily to available Wi-Fi systems, and has the benefit of commonality among college students and does not stigmatize the user as a person with a disability. Each participant is also provided with individualized training for use iPad apps selected to support his or her individual biopsychosocial needs. This study aimed to assess participants' perspectives on technology at baseline, and the perceived benefit of
Table 1

Primary apps reportedly used by students

\begin{tabular}{|c|c|c|}
\hline Application & Frequency & Percent \\
\hline Alarms & 1 & 0.9 \\
\hline American Express & 1 & 0.9 \\
\hline Audible & 1 & 0.9 \\
\hline AudioNote & 9 & 8.3 \\
\hline Awesome Memory & 1 & 0.9 \\
\hline Blackboard Learn & 1 & 0.9 \\
\hline Boggle & 1 & 0.9 \\
\hline Brain Challenge & 1 & 0.9 \\
\hline Breathe2Relax & 1 & 0.9 \\
\hline Calendar & 11 & 10.1 \\
\hline CalenMob/TinyCalendar & 1 & 0.9 \\
\hline Clockwork Brain & 5 & 4.6 \\
\hline Cozi & 2 & 1.8 \\
\hline Evernote & 3 & 2.8 \\
\hline Excel for iPad & 1 & 0.9 \\
\hline Facebook & 1 & 0.9 \\
\hline Goodreader & 1 & 0.9 \\
\hline Google Calender & 1 & 0.9 \\
\hline Google Chrome & 2 & 1.8 \\
\hline iStudiez & 1 & 0.9 \\
\hline JotNot Pro & 1 & 0.9 \\
\hline Kahn Academy & 5 & 4.6 \\
\hline Kindle & 1 & 0.9 \\
\hline KSU Mobile & 1 & 0.9 \\
\hline Learning Ally & 1 & 0.9 \\
\hline Luminosity & 2 & 1.8 \\
\hline Migraine Tracker & 1 & 0.9 \\
\hline Mobile Learn & 1 & 0.9 \\
\hline MyHomework & 4 & 3.7 \\
\hline Notability & 14 & 12.8 \\
\hline Notes & 3 & 2.8 \\
\hline One Pad & 1 & 0.9 \\
\hline Outlook & 2 & 1.8 \\
\hline Peak & 1 & 0.9 \\
\hline Planner Plus & 1 & 0.9 \\
\hline Quizlet & 2 & 1.8 \\
\hline Reminders & 2 & 1.8 \\
\hline Reminders/Calendars & 1 & 0.9 \\
\hline Skype & 4 & 3.7 \\
\hline StudyBlue & 1 & 0.9 \\
\hline TI-Nspire & 1 & 0.9 \\
\hline Voice Dream & 4 & 3.7 \\
\hline Week Cal & 1 & 0.9 \\
\hline Wolfram Alpha & 2 & 1.8 \\
\hline Word & 1 & 0.9 \\
\hline Yoga Studio & 1 & 0.9 \\
\hline YouTube & 2 & 1.8 \\
\hline Total & 109 & 100 \\
\hline
\end{tabular}

apps after 6 and 12 months of use of the individualized apps respectively.

\section{Method}

\subsection{Participants}

This article describes a component of the larger Project Career study. Project Career participants 
described in this study include 50 undergraduate students enrolled at Kent State University, Boston University, West Virginia University, or other twoand four-year colleges and universities within driving distance of each site's geographic location. Each participant is required to (a) have a diagnosis of TBI and (b) self-report experiencing long-term effects as a result of their TBI.

For this study, data collected between March 2014 and May 2016 was analyzed to assess overall perspectives on technologies at baseline and the perceived benefit of iPad apps after 6 and 12 months of use. As of May 2016, the following assessment forms used for this analysis had been completed: 1) Baseline MPT Assessment, [15] including the Survey of Technology Use form $(\mathrm{N}=86), 2)$ 6-months follow-up Assistive Technology Use Follow-Up Survey: Apps Currently Using $(\mathrm{N}=33)$, and 3) 12-months followup Assistive Technology Use Follow-Up Survey: Apps Currently Using $(\mathrm{N}=17)$. Participants completed the 6- and 12-months Assistive Technology Use Follow-Up Survey: Apps Currently Using form for every app they currently used. As a result, there were a total of 109 completions of the assessment forms for the 50 participants $(33+17)$ at the follow-up points.

\subsection{Data collection}

JBS International, Inc. performs all evaluation and data analysis activities for Project Career. Data was collected between March 2014 and May 2016. Each of the project's three sites employs a Technology and Employment Coordinator (TEC). Project Career uses a formal protocol conducted by the TECs, beginning with an intake interview. The TEC gathers basic demographic information and self-reported medical information used to determine whether or not the individual qualifies for program services. If the student has a TBI and reports experiencing longterm impairments, the student qualifies for program services. Once initial assessments are completed, students receive a combination of the following support services during participation in Project Career:

- Individualized CST in the form of an iPad and apps selected based on the individual needs and capabilities of a student (which may change related to cognitive functioning, coursework, transitions, etc. warranting reassessment) and capabilities of each student
- Hands-on individualized training in the use of the iPad and selected apps

- A mentoring program (electronically or inperson) which pairs peers and/or professionals who are working in the student's field of interest

- Individualized vocational case management services

- Assistance in securing field-based internships and employment after graduation

- A resource-directed job placement and accommodation webinar focused on technology transfer, self-advocacy, and professional networking

- Meetings with TECs to track student's challenges and progress using records of case notes about topics discussed after phone conversations, e-mail exchanges, and each student meeting (either in-person or video conference)

Students are eligible to receive TEC services for 12 -months post-graduation. If students choose to pursue further education (graduate degree, certificate program, etc.), however, they are eligible to remain in the program until its completion.

\subsection{Instruments}

Two measures were used in this study. A baseline assessment is performed by the TEC using employment-related attitudinal and behavioral measures that assess the student's employability maturity, career decidedness, career self-efficacy, acceptance and perception of disability, and employment history. Each participant is then given the MPT Assessment (including the Survey of Technology Use form), which measures perspectives on and experiences with technology, current supports, and self-ratings of abilities in areas of reading skills, comprehension, schedule and time management, hearing, seeing, etc. [15].

Once the initial assessments are completed, students were re-evaluated at the 6- and 12-month marks, using the same assessments used at baseline. The Assistive Technology Use Follow-Up Survey: Apps Currently Using form was used at these points to collect information regarding how many hours the apps are being used, which apps students are using, and the perceived usefulness and helpfulness of the apps. At 12-months after graduation, students completed a post-graduation survey to assess employment status, income, hours worked, and continued app use and usefulness. 
From this form, two single item questions related to the perceived benefit of the apps were of particular interest. The first question asked participants to rate how much the app improved their quality of life (1 Not at all; 2 - A little bit; 3 - Neutral effect; 4 - A moderate amount; 5 - A lot). The second question asked participants to rate how much the app helped their academic performance $(1-$ Not at all; $2-$ A little bit; 3 - Neutral effect; 4 - A moderate amount; 5 A lot). As noted previously, participants completed this form for every app they have been using for an extended period of time. See Fig. 1 for the flow of assessment collection.

\subsection{Descriptives and frequency analysis}

All statistical analyses were performed using the Statistical Package for the Social Sciences (SPSS) for Mac version 20. Analyses included descriptives and frequencies. Participant scores on the follow-up Assistive Technology Use Follow-Up Survey: Apps Currently Using form were converted to average scores for each participant. Since the 6-month form was completed by 33 participants, 33 average scores were included in this analysis. Since the 12-month form was completed by 17 participants, 17 average scores were included in this analysis.

Scores for each participant on the Assistive Technology Use Follow-Up Survey: Apps Currently Using form at 6 and 12 months were converted to average scores for each time point for each participant resulting in a total of 33 and 17 unique data points at 6 and 12 months respectively.

\section{Results}

Scores for perspectives on technology on the Survey of Technology Use form could range between 8 and 24 , with lower scores indicating more positive perspectives on technologies. The average score for all participants at baseline was $11.27(\mathrm{SD}=3.14)$, indicating positive perspectives on technology overall. Results from the Assistive Technology Use Follow-Up Survey: Apps Currently Using form showed that, at 6 months $(\mathrm{N}=33), 67 \%$ of participants reported that using iPad apps had moderate or a lot of improvement with their quality of life and $76 \%$ of participants reported that apps provided moderate or a lot of help with academic performance. At 12 months $(\mathrm{N}=17), 65 \%$ of participants reported that using iPad apps had moderate or a lot of improvement with their quality of life and $82 \%$ of participants reported that apps provided moderate or a lot of help with academic performance. Additional frequency analyses revealed that, in total, participants included for this analysis reported current, primary use of 47 unique apps, as shown in Table 1. Six-month scores showed that on a typical day, the students reported using apps for 2.24 hours/day. Most participants (79\%) reported they use their apps "always," "nearly always," or "about half the time" while out in the community. At the 12-month re-evaluation, students reported using apps for 1.94 hours/day and $71 \%$ reported using their apps "always," "nearly always," or "about half the time" while out in the community.

\section{Discussion}

Results suggest that, on average, students with a TBI have positive perspectives on technology use. Most importantly, consistent with Leopold et al. (2015), this provides support for the finding that CST can be beneficial to individuals with a TBI [11]. Specifically, results from this study indicate that most participants found that students reported apps improved their quality of life and helped them perform academically. These results suggest that Project Career TECs were successful in identifying apps that addressed individual student needs and effectively trained students in their use.

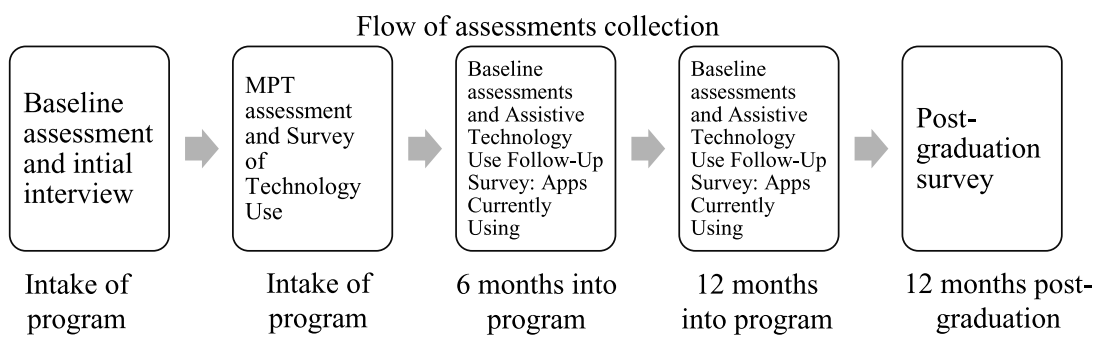

Fig. 1. Flow of assessments collection. 
A limitation of this study is the small sample size. Caution should be exercised when interpreting these results and applying them to all college and university students with a TBI. Project Career is a development project without a control group against which comparisons of program effectiveness can be made. There are no controls over the use of the CST device or apps.

Future research is needed to more fully understand the applicability and effectiveness of CST in the form of iPad apps for individuals with a TBI. The results from this development project are encouraging as they indicate that this population may benefit from apps in their daily life and academic settings. Many apps are now available that can help compensate for cognitive impairments and their benefit for students with a TBI in academic and employment settings should be further explored. Studies are needed to identify specific apps that are most effective in enhancing performance for individuals with a TBI in the academic and vocational spheres. Ideally, future research findings will be useful in guiding professionals as they individualize recommendations during technological referrals. Specific apps may prove to be the gold standard for improving performance in individuals with deficits in organization, memory, or language. Other apps may prove to enhance overall wellness or improve mental health, leading to higher rates of employment.

\section{Conclusion}

College and university students with a TBI are successfully using CST in and out of the classroom. The use of iPad apps improves their perceived quality of life and helps them perform academically. Further research is needed to determine which specific apps are most beneficial. In order to effectively refer students to resources individualized to their unique needs, further research should focus on which apps work best for specific cognitive challenges within this population.

\section{Acknowledgments}

We would like to acknowledge Anneliese Tung for her contributions toward this paper.

\section{Conflict of interest}

None to report.

\section{References}

[1] Centers for Disease Control and Prevention, National Center for Injury Prevention and Control, Division of Unintentional Injury Prevention [webpage on the Internet]. Atlanta, GA; 2016. [updated 2016, Jan 22; cited 2016 May 9]. Available from: http://www.cdc.gov/trauma ticbraininjury/get_the_facts.html

[2] Basso A, Previgliano I, Servadei F. Neurological disorders: A public health approach, Section 3.10 Traumatic brain injury. In World Health Organization Neurological disorders: Public health challenges. (pp. 164-175) Switzerland; 2006. Available from: http://www.who.int/mental_health/ neurology/chapter_3_a_neuro_disorders_public_h_challeng es.pdf

[3] Centers for Disease Control and Prevention, National Center for Injury Prevention and Control. Report to Congress on mild traumatic brain injury in the United States: Steps to prevent a serious public health problem. 2003. Available from: http://www.cdc.gov/traumaticbraininjury/pdf/mtbireporta.pdf

[4] Defense and Veterans Brain Injury Center. (2016). DoD Worldwide Numbers for TBI. Retrieved from http://dvbic. dcoe.mil/dod-worldwide-numbers-tbi

[5] Corrigan JD, Whiteneck G, Mellick D. Perceived needs following traumatic brain injury. Journal of Head Trauma Rehabilitation 2004;19(3):205-16.

[6] Kennedy MRT, Krause MO, Turkstra LS. An electronic survey about college experiences after traumatic brain injury. NeuroRehabilitation 2008;23(6):511-20.

[7] Nardone A, Sampson E, Stauffer C, Leopold A, Jacobs K, Hendricks DJ, Elias E, Chen H, Rumrill P. Project Career: A qualitative examination of five college students with traumatic brain injuries. NeuroRehabilitation 2015;37(3):459-69.

[8] Todis B, Glang A. Redefining success: Results of a qualitative study of postsecondary transition outcomes for youth with traumatic brain injury. Journal of Trauma Rehabilitation 2008;23(4):252-63.

[9] Ponsford JL, Downing MG, Olver J, Ponsford M, Acher R, Carty M, Spitz G. Longitudinal follow-up of patients with traumatic brain injury: Outcome at two, five, and ten years post-injury. Journal of Neurotrauma 2014;31(1):64-77.

[10] Smith A, Rainie L, Zickuhr K. College students and technology. Pew Research Center. 2011. Available from: http://www.pewinternet.org/2011/07/19/collegestudents-and-technology/

[11] Leopold A, Louri A, Petras H, Elias E. The use of assistive technology for cognition to support the performance of daily activities for individuals with cognitive disabilities due to traumatic brain injury: The current state of the research. NeuroRehabilitation 2015;37(3):359-78.

[12] Hartmann KD. Assistive technology: A compensatory strategy for work production post mild brain injury. Work 2010;36(4):399-404.

[13] Holzberg E. The best practice for gaining and maintaining employment for individuals with traumatic brain injury. Work 2001;16(3):245-58.

[14] Scherer MJ. Assistive technologies and other supports for people with brain impairment. New York: Springer Publishing $\mathrm{Co} ; 2012$.

[15] Scherer M. Matching person and technology. Webster, NY: Institute for Matching Person \& Technology. 1998.

[16] Federici S, Scherer M. Assistive Technology Assessment Handbook. Boca Raton, FL: Taylor \& Francis Group; 2012. 